\title{
Pediatric myelodysplastic syndromes
}

\author{
Inga Hofmann ${ }^{1,2}$
}

Received: 22 June 2015 / Accepted: 7 July 2015 / Published online: 26 July 2015

(C) Springer-Verlag Berlin Heidelberg 2015

\begin{abstract}
Pediatric myelodysplastic syndromes (MDS) are a group of rare clonal hematopoietic stem cell disorders characterized by varying degree of cytopenias, ineffective and dysplastic hematopoiesis, and the risk of leukemic transformation. The clinical, laboratory, and histologic presentation of pediatric MDS shares significant overlap with other inherited and acquired bone marrow failure (BMF) disorders. Given that the majority of pediatric patients with MDS present with a hypocellular bone marrow, the histopathologic diagnosis is challenging and usually requires ancillary molecular studies. While rapid advancements have been made in the field of adult MDS, the underlying genetics and pathophysiology of pediatric MDS are still poorly understood. The recent discovery of germline mutations in GATA2 leading to MDS suggests that some pediatric and young adult patients with MDS have an underlying genetic predisposition. Nevertheless, the molecular underpinnings remain poorly understood in most cases. Hematopoietic stem cell transplantation (HSCT) is the only curative treatment option. Optimal timing of HSCT is not often straightforward, as some pediatric patients with lowgrade MDS have an indolent disease course while others show rapid progression to advanced MDS and leukemia. Lastly, the classification of pediatric MDS has evolved over the years and is different from the terminology currently used in adult MDS. This review will focus on the current classification schemes of
\end{abstract}

Inga Hofmann

Inga.Hofmann@childrens.harvard.edu

1 Pediatric Hematology/Oncology, Dana-Farber/Boston Children's Cancer and Blood Disorders Center Boston, Boston, MA, USA

2 Department of Pathology, Boston Children's Hospital, Harvard Medical School, 300 Longwood Ave, Bader 124.1, Boston, MA 02115, USA pediatric MDS and address clinical, laboratory, and pathologic features, as well as diagnostic criteria, genomic advances, and therapeutic options and prognosis.

Keywords Myelodysplastic syndromes $\cdot$ Refractory cytopenia of childhood (RCC) - Refractory anemia with excess blasts (RAEB) · Bone marrow failure · GATA2 haploinsufficiency $\cdot$ Histopathology

\section{Introduction}

The myelodysplastic syndromes (MDS) are a heterogeneous group of clonal hematopoietic stem cell disorders characterized by varying degree of cytopenias, ineffective and dysplastic hematopoiesis, and the risk of leukemic transformation. Pediatric MDS accounts for $\sim 4 \%$ of all pediatric hematologic malignancies $[32,34]$ and has an estimated annual incidence of approximately $1.8-4$ cases per million children. While the median age of diagnosis is 6.8 years, the disease can occur in any age group. The male to female distribution of these disorders appears to be equal $[34,50,63,67]$.

Pediatric MDS can occur de novo without an apparent underlying cause (primary MDS). Secondary MDS can develop after chemo or radiation therapy, in association with an inherited bone marrow failure syndrome (IBMFS) or following an acquired bone marrow failure disorder (BMF), such as idiopathic acquired aplastic anemia (AA) or as a result of a genetic predisposition. Pediatric MDS, IBMFS, and AA represent a spectrum of conditions that share significant overlap. The majority of cases present with hypocellular bone marrow (BM), making them difficult to distinguish from acquired and inherited BMF disorders [54]. Additionally, BMF disorders can progress to MDS, further complicating diagnosis. Recent advancements in genomics have improved our understanding 
of adult MDS, but little is known about the genetic events that lead to pediatric MDS. As a result, no targeted therapies are available and hematopoietic stem cell transplantation (HSCT) remains the only curative therapy.

In this article, we review and critique the current classification system for pediatric MDS outlined in the 2008 World Health Organization (WHO) Classification of Tumors of Hematopoietic and Lymphoid Tissues. In addition, we review the clinical presentation, diagnostic work-up, histopathologic features, and classification of pediatric MDS and highlight important differences between pediatric and adult MDS. We review recent advancements in the genetics and genomics of adult MDS and their applicability to pediatric cases. Finally, we review the current available therapies and prognosis of pediatric MDS.

\section{A historical perspective}

MDS was first described by Giovanni Antonio Di Guglielmo in the 1920 s as "il morbo Di Guglielmo" or chronic erythremic myelosis [6]. In the 1960s and 1970s, the prevailing terms used were "preleukemia" or "smoldering leukemia." In an attempt to better classify these disorders, the first formal classification scheme was introduced in 1976 by the French-American-British Cooperative Group (FAB) as "dysmyelopoietic syndromes" and later, in 1982, using the modern term "myelodysplastic syndromes" (MDS). The FAB classification included 5 categories of MDS: (1) refractory anemia (RA), (2) refractory anemia with ringed sideroblasts (RARS), (3) refractory anemia with excess blasts (RAEB), (4) RAEB in transformation (RAEB-T), and (5) chronic myelomonocytic leukemia (CMML). This classification system established the basis for the WHO classification introduced in 2000, which was further updated in 2008 to accommodate newer diagnostic findings (blast count, degree of dysplasia, and cytogenetic changes).

\section{Development of a pediatric classification}

In response to the limited literature on pediatric MDS, Hasle and colleagues advanced a pediatric classification in 2003 that built on the 2000 WHO classification [33]. These guidelines established the first diagnostic criteria for pediatric MDS, requiring the presence of at least two of the following: (1) sustained unexplained cytopenia, (2) at least bilineage morphologic myelodysplasia, (3) acquired clonal cytogenetic abnormality in hematopoietic cells, or (4) increased BM blasts ( $>5 \%$ ) [33]. In addition, juvenile myelomonocytic leukemia (JMML) and MDS associated with Down syndrome were recognized as distinct entities and are therefore discussed separately in this special issue (please refer to Cantor and Calvo et al. in this issue).
This first pediatric MDS classification was crafted to address two challenges: (1) to distinguish MDS with a low blast count from acquired AA and other BMF conditions and (2) to differentiate MDS with excess blasts (RAEB) from de novo acute myeloid leukemia (AML). Based on this classification scheme, pediatric MDS was divided into three main categories: refractory cytopenia (RC), RAEB, and RAEB-T (Table 1).

In recent years, the community has come to recognize that there are major differences between pediatric and adult MDS. Pediatric patients commonly present with thrombocytopenia and neutropenia, as opposed to isolated anemia [45]. Therefore, the term refractory cytopenia (RC) was used in children rather than refractory anemia (RA), which is used in adults. In addition, RARS and deletions in 5q- are rare in children [5, 31-33, 50, 64, 67, 69, 79]. If ringed sideroblasts are observed in a pediatric BM, other etiologies particularly nutritional deficiencies, drug toxicity, and congenital sideroblastic anemias, including Pearson marrow-pancreas syndrome, should be considered [19, 48]. Building on the pediatric proposal by Hasle in 2003 [33], the 2008 WHO classification introduced a pediatric MDS classification for the first time [45].

\section{Current classification of pediatric MDS}

The current WHO classification updated the term RC to refractory cytopenia of childhood (RCC). The diagnostic categories for pediatric MDS are largely distinguished by the peripheral blood $(\mathrm{PB})$ and bone marrow $(\mathrm{BM})$ blast percentage (see Table 1) [13].

\section{Refractory cytopenia of childhood}

RCC is the most common subtype of pediatric MDS accounting for about $50 \%$ of cases $[54,63]$. The majority of patients present with hypocellular BM resembling acquired or inherited BMF conditions [53]. The presence of a clonal cytogenetic marker can confirm the diagnosis; however, about $61-67 \%$ of patients with RCC have normal cytogenetics [53].

One of the drawbacks of the WHO classification is that the provisional entity of RCC includes a wide range of phenotypes, ranging from hypo- to hyper-cellular RCC with limited unilineage dysplasia to overt multilineage dysplasia. RCC with multilineage dysplasia (RCMD) is easily appreciated as unequivocal MDS. In contrast, hypocellular RCC with minimal or unilineage dysplasia is difficult to distinguish from acquired AA and IBMFS. As opposed to adults where it is prognostic $[25,52,83]$, the implications of multilineage (compared to unilineage) dysplasia is uncertain in childhood [14, 33]. Therefore, the recommendation was made to group all pediatric MDS without excess blasts into the RCC category, regardless of the degree of dysplasia and cellularity. 
Table 1 Classification of childhood MDS

\begin{tabular}{lll}
\hline Diagnostic category & PB blasts \% & BM blasts \% \\
\hline Refractory cytopenia of childhood (RCC) & $<2$ & $<5$ \\
Refractory anemia with excess blasts (RAEB) & $2-19$ & $5-19$ \\
RAEB in transformation (RAEB-T) & $20-29$ & $20-29$ \\
\hline
\end{tabular}

Adapted from WHO classification of neoplastic diseases of the hematopoietic and lymphoid tissue (2008) [15]

Recent studies suggest that the category of RCMD in pediatric MDS patients might be of prognostic value since pediatric RCC patients with multilineage dysplasia have a significantly higher incidence of disease progression [29].

\section{Differentiating severe aplastic anemia from hypocellular refractory cytopenia of childhood}

Due to limitations in the reproducibility of the diagnostic criteria and limited data on the clinical implications [29, 90], the provisional diagnosis of RCC remains controversial. The WHO defines RCC as (1) dysplasia in one or more hematopoietic lineages or in at least $10 \%$ of cells in one cell line and (2) less than $5 \%$ blasts in the marrow [13]. Given the challenges in differentiating hypocellular RCC from acquired AA, the WHO outlined key histological differences present in the BM between the two disorders (Table 2; Fig. 1), which heavily relies on a topographic diagnosis with specific histologic patterns. It is important to note that patients with IBMFS such as Fanconi anemia (FA), dyskeratosis congenital (DC), or Shwachman-Diamond syndrome (SDS) resemble the histologic features of RCC [17, 33, 92]. Therefore, these conditions must be excluded by molecular testing.

Few studies have assessed the validity of the current classification and the provisional entity of RCC [7, 29, 90]. Forester et al. assessed the reproducibility and clinical implications of the current criteria for RCC and AA outlined in a retrospective single-center study of pediatric patients diagnosed with AA [22]. They found that concordance between pathologists in the diagnosis of AA or RCC was modest and the diagnosis of RCC was not prognostic of immunosuppressive therapy (IST) treatment failure. Interestingly, studies by Forester ${ }^{23}$ and Yang ${ }^{27}$ both suggest that there is a correlation between moderately severe AA (MAA) and RCC $[22,90]$. In addition, Forester et al. found a low rate $(<5 \%)$ of clonal evolution, which was observed exclusively in patients classified as MAA. This evidence suggests that, if it were possible, precise separation of severe AA from hypocellular RCC might help predict development of clonal disease [7, 22].

While some studies suggest that the classification of RCC is valuable and reproducible [7], others suggest that the diagnosis is difficult to establish with certainty [22] and does not accurately predict response and outcomes after IST $[22,29]$. Although the development of clonal hematopoiesis exclusively observed in patients classified as MAA [22] and RCC [7] is intriguing, this needs to be confirmed in larger prospective studies.

\section{Advanced MDS}

The classification of advanced pediatric MDS is based on the morphology and blast count in the BM. The WHO classification divides advanced pediatric MDS into two categories: (1) RAEB-1 (5-10 \% blasts) or RAEB-2 (11-19 \% blasts) and (2) RAEB-T (20-29\% blasts).

The blast cutoff for the diagnosis of AML was historically set at $30 \%$ and had been lowered to $20 \%$ for pediatric and adult de novo AML. Therefore, the category of RAEB-T,

Table 2 Histopathologic criteria of hypocellular RCC and SAA as outlined in the WHO classification

\begin{tabular}{|c|c|c|}
\hline $\begin{array}{l}\text { Lineage } \\
\text { characteristics }\end{array}$ & $\mathrm{RCC}$ & SAA \\
\hline Erythroid & $\begin{array}{l}\text { Patchy, left-shifted } \\
\text { erythropoiesis with } \\
\text { increased mitoses }\end{array}$ & $\begin{array}{l}\text { Lacking foci or left- } \\
\text { shifted erythroid cells } \\
\text { or only showing single } \\
\text { small focus of }<10 \text { cells } \\
\text { of erythroid cells with } \\
\text { maturation }\end{array}$ \\
\hline Myeloid & $\begin{array}{l}\text { Markedly decreased, } \\
\text { left-shifted } \\
\text { myelopoiesis }\end{array}$ & $\begin{array}{l}\text { Lacking or markedly } \\
\text { decreased } \\
\text { myelopoiesis with very } \\
\text { few small foci of } \\
\text { granulopoiesis with } \\
\text { maturation }\end{array}$ \\
\hline \multirow[t]{2}{*}{ Megakaryocytes } & $\begin{array}{l}\text { Markedly decreased } \\
\text { megakaryopoiesis }\end{array}$ & $\begin{array}{l}\text { Lacking or only very few } \\
\text { megakaryocytes } \\
\text { present }\end{array}$ \\
\hline & $\begin{array}{l}\text { Dysplastic changes } \\
\text { (micromegakaryocytes) }^{\mathrm{a}}\end{array}$ & $\begin{array}{l}\text { No dysplastic changes or } \\
\text { micromegakaryocytes* }\end{array}$ \\
\hline Lymphoid & $\begin{array}{l}\text { Lymphocytes, PC, MC } \\
\text { may be focally } \\
\text { increased or dispersed }\end{array}$ & $\begin{array}{l}\text { Lymphocytes, PC, MC } \\
\text { may be focally } \\
\text { increased or dispersed }\end{array}$ \\
\hline CD34+ cells & Not increased & Not increased \\
\hline
\end{tabular}

Adapted from the 2008 WHO classification [15]

$P C$ plasma cells, $M C$ mast cells

${ }^{\text {a }}$ Immunohistochemistry with CD61 staining is required for the detection of micromegakaryocytes 


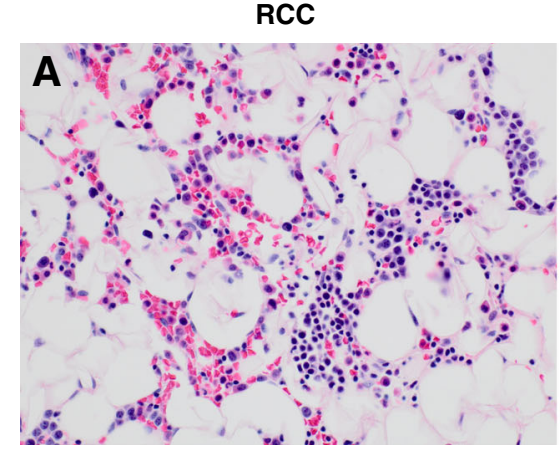

Fig. 1 Histology of hypocellular refractory anemia of childhood (RCC) compared to severe aplastic anemia $(S A A)$. a The image shows an example of a child's marrow with hypocellular RCC (left) and illustrates a hypocellular marrow with patches of erythroid predominant hematopoiesis (BM). Erythroid islands show increased early forms, mitosis, and occasional nuclear contour abnormalities. Scattered mildly left-shifted myeloid elements are noted in the background.

which is based on an old FAB category, was omitted in the recent WHO classification of adult MDS and these cases are now regarded as AML with myelodysplastic-related changes (AML-MRC). In contrast, RAEB-T continues to be recommended in the current pediatric classification $[30,33,55]$ given that there is little evidence that a blast cutoff of $20 \%$ is of clinical significance.

In the absence of correlative data, the blast cutoff for the definition of AML is arbitrary and, in reality, the transition of MDS to AML is likely a continuum. Nevertheless, the different terminologies in the pediatric and adult classification have introduced confusion. These classification schemes are not universally applied in the literature of pediatric MDS further complicating the interpretation of clinical outcomes.

\section{Challenges of the current WHO classification}

The WHO classification is the current standard for diagnosis of pediatric MDS. While these guidelines allow for accurate classification of most pediatric MDS [17], there are several limitations that need to be addressed in future editions.

First, classification based on blast count alone is a crude method of distinguishing clinical phenotypes. With the advent of next generation sequencing (NGS), additional molecular markers may emerge that can be incorporated into future classifications. Second, the provisional entity of RCC includes a wide range of phenotypes that might be due to different underlying molecular genetics. For example, the lack of differentiation of cellularity and degree of dysplasia, in particular the exclusion of RCMD from the classification, makes it difficult to interpret clinical studies. Finally, the different terminologies and definitions used for advanced MDS in pediatric and adult patients cause confusion. For this reason, it is important to use consistent contemporary terms and definitions.

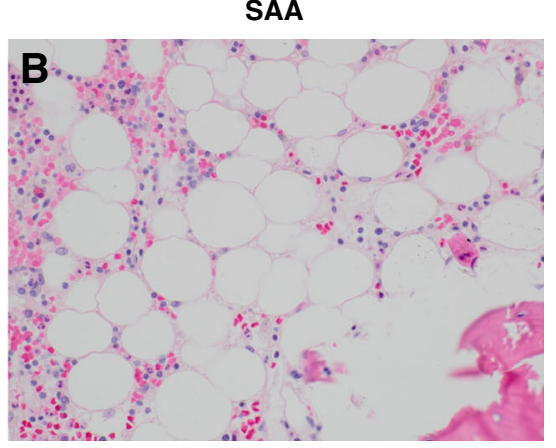

Megakaryocytes are not present. b In contrast, an image of a marrow from a child with severe aplastic anemia (SAA) (right) shows a severely hypocellular, adipose-rich marrow with scattered lymphocytes and fully maturing myeloid cells including segmented neutrophils. Clusters of immature erythroid cells are not seen. Megakaryocytes are absent. Magnification $\times 400$

\section{Secondary MDS}

Secondary pediatric MDS can result from a number of inherited predispositions or acquired conditions (Table 3). The underlying molecular mechanisms for these two groups are distinct, and therefore, it is important to segregate them in clinical studies. In cases of constitutional abnormalities associated with MDS, most often an underlying IBMFS with

Table 3 Inherited and acquired conditions associated with pediatric myelodysplastic syndrome (MDS) leading to secondary MDS

Conditions associated with MDS

Inherited conditions

Inherited bone marrow failure syndromes (IBMFS)

Fanconi anemia

Shwachman-Diamond syndrome

Severe congenital neutropenia

Dyskeratosis congenita

Diamond-Blackfan anemia

GATA2 haploinsufficiency (MonoMac syndrome, Emberger syndrome, Familial MDS/AML)

Other familial non-syndromic MDS (ETV6, RUNX1/AML1, CEBPA)

Familial MDS (at least one first degree relative with MDS/AML) without identified genetic cause ${ }^{\mathrm{a}}$

Trisomy 8 mosaicism

Acquired conditions

Prior chemotherapy

Prior radiation therapy

Acquired aplastic anemia ${ }^{\mathrm{b}}$

${ }^{\text {a }}$ Familial cases of MDS not due to GATA2, ETV6, RUNX1/AML1 and CEBPA

${ }^{\mathrm{b}}$ A subset of cases currently classified as acquired aplastic anemia might be due to underlying genetic predisposition and may in the future be considered as an inherited condition (see main text) 
defects in DNA repair, telomere biology or ribosomal protein synthesis is present. Other genetic predisposition syndromes such as trisomy 8 mosaicism and GATA2 haploinsufficiency have been described (Table 3).

Therapy-related MDS after chemo or radiation therapy causes DNA damage and most frequently involves changes in chromosomes 7, 5, and 11q23, which are observed in more than $90 \%$ of the cases $[1,78]$. Therapy-related MDS more often presents as advanced MDS.

Secondary MDS following IST for AA has traditionally been regarded as an acquired cause of secondary MDS [17, 33] although it is possible that some pediatric patients regarded as acquired $\mathrm{AA}$ in fact have an underlying inherited genetic predisposition, possibly explaining the poor outcomes of some AA patients with clonal progression to MDS.

The diagnosis of secondary MDS following IBMFS or more recently identified cases of GATA2 haploinsufficiency is challenging as most bone marrows from patients with IBMFS show some background dysplasia. For example, dysmyelopoiesis (in particular in the neutrophil series) is often seen in SDS [88]. Patients with GATA2 haploinsufficiency show unique megakaryocytic dysplasia with large separated, "pulled apart" appearing nuclei, that often precedes the development of MDS $[12,74]$ [internal observation from the pediatric MDS and BMF Registry]. Therefore, minimal diagnostic criteria for secondary MDS following an underlying IBMFS have been developed [33] (increased BM blast count, development of a hypercellular marrow in the presence of persistent PB cytopenias and acquired clonal chromosomal abnormalities). However, studies in FA and SDS indicate that clonal cytogenetic abnormalities are not universally associated with disease progression and poor outcomes since cytogenetic changes may persist for years without evolution to MDS/ AML $[3,4,51]$.

Patients with IBMFS, such as FA, frequently present with a morphological picture of RCC [92]. Therefore, it is also difficult to distinguish primary pediatric MDS from IBMFS, further highlighting the importance of molecular testing.

\section{Clinical presentation}

The clinical presentation in pediatric MDS patients is variable. Some patients, especially those with RCC, come to medical attention because of an incidental finding of cytopenia [45]. In other cases, patients present with symptoms related to cytopenias. In contrast to adult MDS, most pediatric MDS patients present with bleeding due to thrombocytopenia or infection secondary to neutropenia. Isolated anemia is less frequently seen in children. If anemia is present, it is usually macrocytic and accompanied by thrombocytopenia or neutropenia.

\section{Diagnostic work up}

\section{Laboratory evaluation}

Given that MDS is often a diagnosis of exclusion, the workup of patients with suspected MDS requires a comprehensive laboratory evaluation to rule out secondary causes (Table 4).

A number of non-hematologic disorders can cause cytopenias and a hypoplastic marrow in children and must be ruled out, including vitamin and mineral deficiencies and zinc toxicity [23], viral infections and toxin or drug exposure [10], rheumatologic disorders (juvenile rheumatoid arthritis), mitochondrial disorders (Pearson syndrome), metabolic disorders (mevalonate kinase deficiency) and inherited anemias (e.g., CDA), and IBMFS [53].

\section{Histopathology}

First, careful evaluation of the PB smear to assess morphological abnormalities and the presence of circulating blasts should be performed. Both a high-quality BM aspirate and biopsy are required for an accurate assessment. The BM aspirate allows for assessment of cytologic dysplasia and blast count, while the biopsy is essential to assess cellularity, the presence of reticulin fibrosis, and the marrow architecture. It may also facilitate the identification of dysplastic megakaryocytes. A biopsy is particularly important for the assessment of pediatric MDS as the majority of patients present with a hypocellular marrow that has patches of cellularity that may be missed on a sub-optimal, hypospicular aspirate.

In addition to routine May-Grunwald-Giemsa-stained BM aspirate and H\&E-stained biopsy slides, a number of ancillary immunohistochemistry (IHC) and special stains are often needed. The WHO classification for MDS in childhood mandates the addition of a CD61 or CD41 stain to identify micromegakaryocytes, which are supportive of the diagnosis of RCC and important in the differentiation from acquired AA. Additional lineage- or stage-specific IHC stains (CD34, CD117 (C-KIT), CD71, glycophorin A, MPO, and lysozyme) can also be helpful. Other IHC studies such as CD3, CD20, CD79a, and TdT, to assess lymphoid populations, are indicated when an increase in lymphocytes is observed, which can often be noted in younger children or in a reactive process. A reticulin stain is helpful in the assessment of background fibrosis (associated with monosomy 7 and germline GATA2 mutations) $[12,24,74]$.

\section{Cytogenetics and molecular studies}

Routine karyotype and fluorescence in situ hybridization (FISH) for 7-, 7q-, 5q, +8, 20q- and MLL (11q23) rearrangements should be performed in all patients with suspected MDS. 
Table 4 Suggested diagnostic workup for pediatric patients with suspected MDS

\begin{tabular}{|c|c|}
\hline agnostic checklist & \\
\hline Basic laboratory & $\begin{array}{l}\checkmark \text { CBC with differential (ANC, AMC) } \\
\checkmark \text { Reticulocyte count } \\
\checkmark \text { Basic chemistry studies (electrolytes, LDH, uric acid) } \\
\checkmark \text { Renal and liver function tests } \\
\checkmark \text { Hemoglobin F (hemoglobin electrophoresis) }\end{array}$ \\
\hline Immunology & $\checkmark$ Lymphocyte subsets (B and T cell subsets) \\
\hline Other laboratory & $\begin{array}{l}\checkmark \text { High-resolution HLA typing } \\
\checkmark \text { Nutritional deficiencies (folate, B12, copper) } \\
\checkmark \text { Infectious studies (CMV, EBV, HSV, parvovirus B19, VZV, HIV, leishmaniasis, etc.) }\end{array}$ \\
\hline Bone marrow failure workup & $\begin{array}{l}\checkmark \text { Fanconi anemia (chromosomal breakage with DEB from PB) } \\
\checkmark \text { Dyskeratosis congenita (telomere length in lymphocyte subsets, gene sequencing as indicated }{ }^{\mathrm{b}} \text { ) } \\
\checkmark \text { Shwachman-Diamond syndrome (SBDS gene sequencing, isoamylase, stool elastase) } \\
\checkmark \text { Other IBMFS based on clinical index of suspicion } \\
\checkmark \text { PNH clone on PB by flow cytometry }\end{array}$ \\
\hline Molecular diagnostics & $\begin{array}{l}\checkmark G A T A 2 \text { (on all cases) } \\
\checkmark C B B P A, R U N X 1 / A M L 1, E T V 6 \text { based on clinical suspicion in cases of familial MDS }\end{array}$ \\
\hline Histopathology & $\begin{array}{l}\checkmark \text { Peripheral blood smear review } \\
\checkmark \text { Bone marrow aspirate for morphology } \\
\checkmark \text { Bone marrow biopsy for histology } \\
\checkmark \text { IHC staining (at minimum CD34 and CD61 suggested) } \\
\checkmark \text { Reticulin stain } \\
\checkmark \text { Iron stain on aspirate }\end{array}$ \\
\hline Additional studies & $\begin{array}{l}\checkmark \text { Flow cytometry } \\
\checkmark \text { Karyotype form BM } \\
\checkmark \text { FISH on BM }(-7,7 \mathrm{q}-,+8,-5,5 \mathrm{q}-, 20 \mathrm{q}-)\end{array}$ \\
\hline
\end{tabular}

$A N C$ absolute neutrophil count, $A M C$ absolute monocyte count, $D E B$ diepoxybutane, $P B$ peripheral blood

${ }^{a}$ High-resolution HLA should be send early on the patient and any full siblings once diagnosis is confirmed

${ }^{\mathrm{b}}$ Gene sequencing should be performed if telomere length shows very short telomeres diagnostic for DC

An underlying IBMFS, particularly FA, DC, or SDS, should be ruled out by molecular testing, as these diagnoses can have cryptic presentations and their presence will impact clinical management. Heterozygous germline mutations in GATA2 can occur in patients with sporadic and familial MDS and therefore should be assessed in MDS patients as well as any potential related HSCT donors [28], [11, 39, 40, $46,75][60]$.

Pediatric MDS and other BMF disorders, in particular those due GATA2 mutations, can present with immunodeficiency. Therefore, an immunology workup with analysis of lymphocyte subsets (B- and T-cell subsets) should be considered.

\section{Flow cytometry}

Flow cytometry to assess blast count and the presence of a PNH clone should also be obtained. While small subclinical $\mathrm{PNH}$ clones can be found in patients with RCC [2], overt PNH with thrombosis and hemolysis is a rare finding in children [81].

In adults, flow cytometry analysis with the assessment of immunophenotypic abnormalities in myelomonocytic, erythroid, and myeloid blast cells can provide complementary information aiding in the diagnosis and distinguishing MDS from other non-clonal cytopenias [87]. However, studies assessing the value of flow cytometry in pediatric patients are limited. Veltroni and colleagues showed that immunophenotypic characterization of advanced MDS in pediatric patients might be a useful diagnostic and prognostic tool in differentiating from de novo AML [82]. Similar to adults, co-expression of $\mathrm{CD} 7$ was associated with poor outcomes [20, 21, 57, 58, 80, 82].

Simple flow cytometric scoring systems first developed by Ogata and others have also been shown to be useful in adult low-grade MDS $[15,56]$. However, the diagnostic utility of flow cytometry scoring in low-grade pediatric MDS, in particular in RCC, remains uncertain. Furthermore, flow 
cytometric analysis for the assessment of abnormal hematopoietic maturation (as a surrogate for dysplasia) requires a highly standardized approach and specialized expertise that is not uniformly available.

\section{Genetics and genomic advances}

\section{Cytogenetics}

The cytogenetic profile of pediatric and adult MDS patients varies significantly. The majority of pediatric MDS cases have a normal karyotype. In pediatric MDS, monosomy 7 is the most commonly observed change, occurring in $30 \%$ of cases [26], followed by trisomy 8 . A complex karyotype involving 3 or more cytogenetic changes occurs only in a small subset of patients and is associated with a poor prognosis [26]. Abnormalities in chromosome 5, in particular the 5- syndrome commonly seen in adults, rarely occur in children. Other changes such as $20 \mathrm{q}$ - and loss of chromosome $\mathrm{X}$ are infrequently seen in children.

\section{Recent genetic advances in MDS}

The advent of novel sequencing technologies has accelerated the pace of discovery in adult MDS. Since the early genetic studies that lead to discovery of somatic mutations in oncogenes $(N R A S / K R A S)$ and tumor-suppressor genes (TP53, $R U N X 1)$ [44, 65, 66], over 40 MDS-associated gene mutations have been discovered in the last 7 years, including identification of epigenetic regulators (TET2, ASXL1, EZH2, $D N M T 3 A$, IDH1/IDH2), and most recently, genes in the splicing machinery (SFRB1, U2AF1, ZRSR2) and cohesion complex genes (STAG2, SMC3, RAD21). In adult MDS, somatic mutations in splicing factors and epigenetic regulators are present in about $75 \%$ of cases, followed by isolated TP53 mutations and mutations in a variety of other genes including transcription factors (RUNX1, ETV6, GATA2, PHF6), kinase signaling (NRAS, KRAS, JAK2, CBL), and cohesion complex genes $[61,85,91]$. Interestingly, the majority of these changes - in particular those of splicing factors and epigenetic regulation - do not appear to be present in children [35], suggesting that pediatric MDS is indeed a distinct disorder. A recent large scale whole-exome sequencing study on DNA samples from over 17,000 individuals showed that patients under the age of 40 years rarely had somatic mutations in adult MDSassociated genes. The most common mutations identified were DNMT3A, TET2, and ASXL1 disease-associated variants, suggesting that mutations in epigenetic pathways accumulate with age and likely play a less prominent role in children [42].

Based on these data, it has been speculated that pediatric MDS is more frequently due to an inherited genetic predisposition. The identification of RUNX1/AML1 in familial platelet disorder with predisposition to AML, CEBPA, and more recently the discovery of germline mutations in GATA2 leading to haploinsufficiency and development of familial MDS/MonoMac syndrome and germline mutations in ETV6 [94] leading to familial MDS, support this. Nevertheless, in contrast to adults, the underlying genetic mechanism remains uncertain for most pediatric MDS patients.

\section{GATA2 diagnostics and unique pathology}

In 2011, heterozygous germline mutations in GATA2 was independently observed in four seemingly distinct disease entities: (1) autosomal dominant familial MDS/AML [27]; (2) Emberger syndrome, characterized by lymphedema, warts, and predisposition to MDS/AML [59]; (3) MonoMac syndrome, comprised of monocytopenia and nontuberculous mycobacterial infection [41, 84]; and (4) dendritic cell, monocyte, and B and natural killer cell lymphoid deficiency (DCML) $[8,9,16]$. It is now recognized that these conditions are a spectrum of hematopoietic, lymphatic, and immune system disorders due to GATA2 haploinsufficiency [74]. Mutations in GATA2 can arise sporadically or be inherited in an autosomal dominant pattern [41, 84]. To date, several different GATA2 mutations have been identified: (1) missense or frameshift mutations often involving the C-terminal zinc finger, which is important for DNA binding, (2) null mutations, and (3) mutations in the regulatory enhancer region of intron $5[16$, 27, 38, 41, 43, 47, 59, 62].

While the clinical hallmarks of GATA2 deficiency are immunodeficiency, predisposition to MDS/AML, pulmonary alveolar proteinosis (PAP), and congenital lymphedema, other clinical phenotypes have been observed, including sensorineural hearing loss, thrombotic events, panniculitis/erythema nodosum, increased incidence of miscarriages, other infections (severe Clostridium difficile, fungal, and EBV), and solid tumors (often related to viral infections including HPV- and EBV-driven leiomyosarcoma). Furthermore, there is significant heterogeneity in the clinical presentation, onset, and severity of the disease with some patients being asymptomatic and other presenting with life-threatening infections or MDS/ AML. Intriguingly, there is also pronounced variation in the expression and severity of phenotypes and onset within a single family. Genotype-phenotype associations have been attempted, but only limited correlations have been found [74].

Patients with GATA2-related BMF disorders and acquired AA show significant overlap in presentation. Ganapathi et al. demonstrated that routine laboratory values, flow cytometry on the PB and BM, BM morphology, and cytogenetic studies can aid in the differential diagnosis and identify those patients for whom GATA2 sequencing is indicated [24]. They found that hemoglobin levels, platelet count, and absolute neutrophil count (ANC) were not as severely decreased in GATA2 
patients compared to AA patients. In contrast, the monocyte and lymphocyte counts were severely decreased in GATA2 patients but usually only mildly reduced in patients with AA [24].

Flow cytometry of the BM has now been shown to be capable of identifying those that are at high risk of carrying a GATA2 mutation. BM of GATA2-mutated patients often show a reduction in monocytes, $B$ cells and NK cells, and a complete loss of B-cell precursors (CD19+, CD10+, CD20-). The loss of hematogones is intriguing and suggests disordered B-cell development. While hematogones are decreased in AA patients, they are usually detectable. Interestingly, the BM of patients with GATA2 mutations showed an increase in overall T cells, an inverted CD4:CD8 ratio, and an expansion of large granular lymphocyte (CD3+, CD16+, CD56+) cells. An increase in myeloid blasts is often noted [12, 24, 84]. CD34+ cells were overall reduced in AA and GATA2 patients compared to controls but similar to each other.

The morphology of BM specimens from GATA2 patients has unique characteristics (Fig. 2). The majority of patients (84\%) meet histomorphologic criteria for MDS often with multilineage dysplasia and less than $5 \%$ blasts [74]. In keeping with most pediatric MDS, patients with GATA2 haploinsufficiency usually show a hypocellular marrow. Using the WHO classification scheme, GATA2 patients would typically be best classified as RCC. A subset of patients present with a hypercellular marrow, often with evidence of advanced MDS (RAEB) or progression to leukemia. This suggests that GATA2 haploinsufficiency can be regarded as an inherited BMF disorder with risk to progression to MDS and AML likely mediated through secondary clonal somatic events.

Based on recent studies [12, 24, 74] and our own observations [36, 37], a unique megakaryocytic dysplasia is the most common finding in $92 \%$ of the patients and can even be seen prior to or without overt progression to MDS [12, 24, 74]. Megakaryocytes are often large and show separated and peripherally placed nuclear lobes, although occasional micromegakaryocytes have been observed in the adult population as well [24]. Other dysplastic features, including erythroid dysplasia with megaloblastoid changes, nuclear contour irregularities and bi-nucleation and myeloid dysplasia characterized by maturation dyssynchrony and hypogranulation, tend to be less frequent, occurring in $50 \%$ of the cases. The myeloid to erythroid ratio is frequently reversed. A varying degree of reticulin fibrosis is also seen in about $50 \%$ of the cases [24].

Clonal cytogenetic abnormalities have been identified in large subset of GATA2 patients. Emerging evidence supports a strong association between GATA2 germline mutations and development of monosomy 7 and trisomy 8 . Other karyotype abnormalities have been seen (gain of 1q and deletions of parts or entire chromosome 6) [24, 74].

Historic reports have described a pediatric entity termed "monosomy 7 syndrome" characterized by MDS, monosomy 7 and a histopathology with leukoerythroblastic anemia with leukocytosis, thrombocytopenia and slight increase in blasts, and increased reticulin in some cases [70]. Most of the early reports on monosomy 7 syndrome ultimately fit the diagnosis of JMML. However, a study by Hasle et al. [31] analyzed myeloid disorders in children, including pediatric MDS, and AML with monosomy 7 some of which were familial in origin. Given the overlap of the clinical features and histologic description with GATA2 patients and the association with monosomy 7 , we can now surmise that a subset of the patients that were historically described as monosomy 7 syndrome or MDS/AML with monosomy 7 and did not fulfill the criteria for JMML are likely cases of GATA2 haploinsufficiency (Fig. 3). These patients may resemble chronic myelomonocytic leukemia (CMML). In fact, CMML can be seen in a small subset of patients with GATA2 haploinsufficiency and might indicate disease progression to a proliferative state with increased myelomonocytic cells [74].

Taken together, the unique clinical and histologic features that are present in patients with GATA2 haploinsufficiency should be carefully evaluated in any pediatric patient with suspected MDS or BMF. The histopathology of GATA2 patients is unique, and in some patients, the megakaryocytic dysplasia is striking enough to provide instant pattern recognition. Because of the clinical and genetic implications for patients with GATA2 haploinsufficiency, genetic testing should be performed on all patients presenting with classical phenotypes of familial MDS, Emberger syndrome, and MonoMac syndrome and be considered in all pediatric patients with MDS or BMF. Given the high association between monosomy 7 and trisomy 8, GATA2 testing should also be considered in patients with hematologic malignancies especially AML. Testing of family members and genetic counseling should be offered to all patients with documented GATA2 mutation but is essential for any related HSCT donors.

\section{Treatment options in pediatric MDS}

HSCT remains the only curative therapy for pediatric MDS. High-resolution HLA typing should be performed early to expedite the search for a matched related donor (MRD) or unrelated donor (URD). Evaluation of any MRD should include a CBC with differential, BM aspirate and biopsy, and cytogenetic and FISH studies to rule out familial MDS. For patients with GATA2 mutation or patients with MDS 

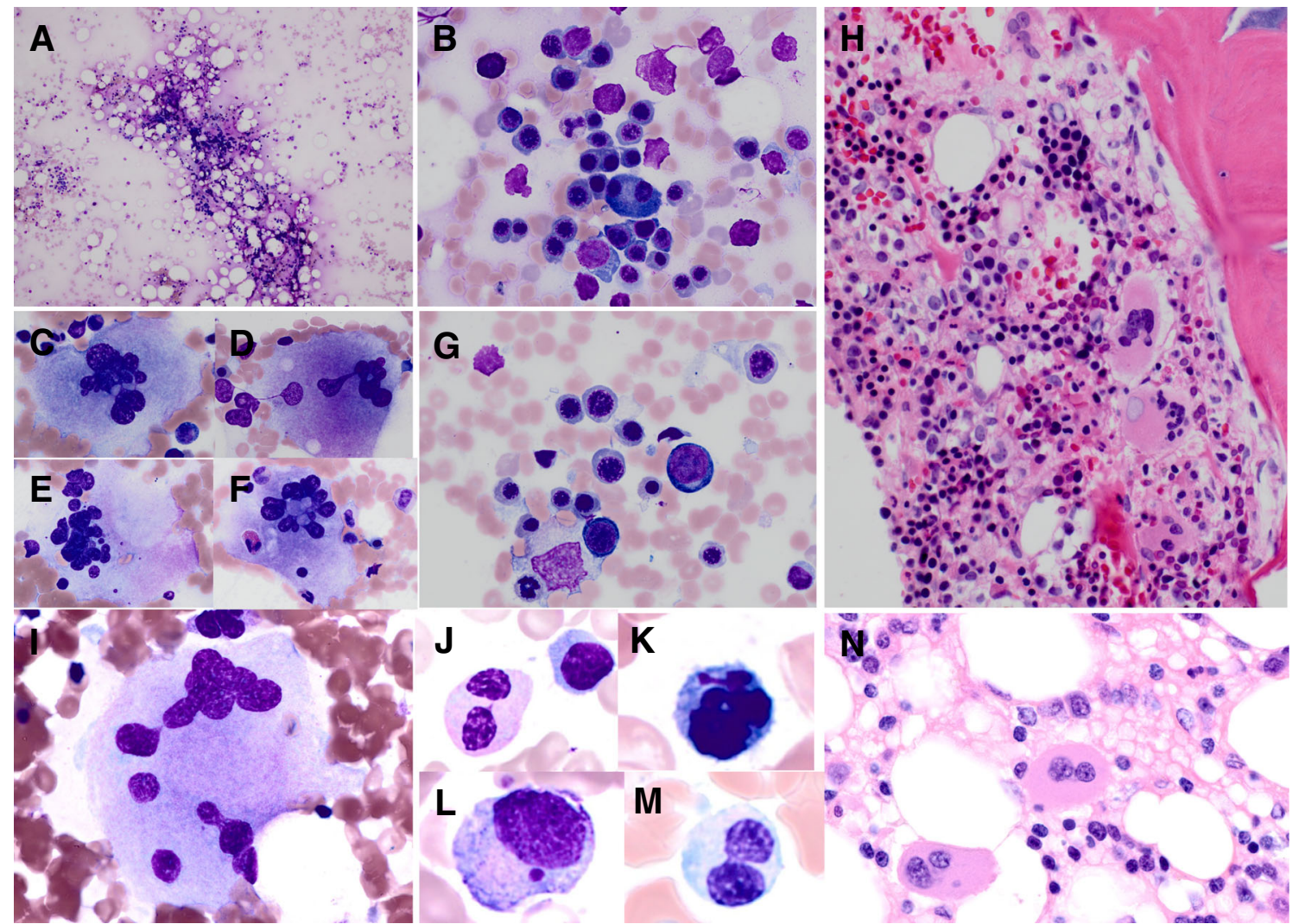

Fig. 2 Unique histopathology in pediatric MDS due to GATA2 mutation. a-g Representative images from the marrow of a 17-year-old male with fevers, lymphadenopathy, and splenomegaly secondary to primary EBV infection. He eventually developed persistent pancytopenia (absolute neutrophil count (ANC) 400 cells/uL, absolute monocyte count (AMC) 0 cells/uL, platelet count $44 \times 10^{3}$ cells/uL) with morphological dysplasia, despite normalizing EBV titers and negative laboratory and molecular work up for HLH. The BM aspirate showed hypocellular spicules (a) $(\times 200)$ with a relative erythroid hyperplasia with megaloblastoid changes and dyserythropoiesis (b and g) $(\times 400)$. Megakaryocytes displayed marked dysplasia with hyperlobated pulled apart nuclei $(\mathbf{c}-\mathbf{f})(\times 1000)$. The biopsy showed a hypocellular marrow with erythroid hyperplasia

secondary to an IBMFS, GATA2 mutations and IBMFS should be ruled out by molecular testing in any possible MRD.

The literature on HSCT outcomes for pediatric MDS is sparse and includes small retrospective studies with a wide range of MDS-related diagnoses, varying pre-transplant therapies and conditioning regimens, stem cell sources, and graft versus host disease (GVHD) prophylaxis. Most studies used a myeloablative-conditioning regimen, although more recently a reduced intensity-conditioning (RIC) approach has successfully been employed in a selected group of patients with lowgrade MDS [76], in an attempt to reduce treatment-related toxicity and mortality.

Several studies indicate that transplanting pediatric MDS patients with RCC prior to disease progression is associated with improved outcomes [73, 89], supporting a referral to HSCT immediately after diagnosis.

The use of pre-HSCT chemotherapy in MDS remains controversial. Historically, pediatric MDS patients with advanced disease (RAEB, RAEB-T) have been treated with AML induction chemotherapy [16]. However, recent data suggest that intensive chemotherapy before HSCT does not improve outcomes or relapse incidence (RI) in most patients with advanced MDS with the exception of MDS with progression to AML ( $>30 \%$ blasts) $[72,77]$. Therefore, expedited HSCT should be considered in most patients with RAEB, particularly if a donor can be available promptly. Induction chemotherapy would uniformly be recommended for patients with MDS with progression to AML and perhaps RAEB-T. 

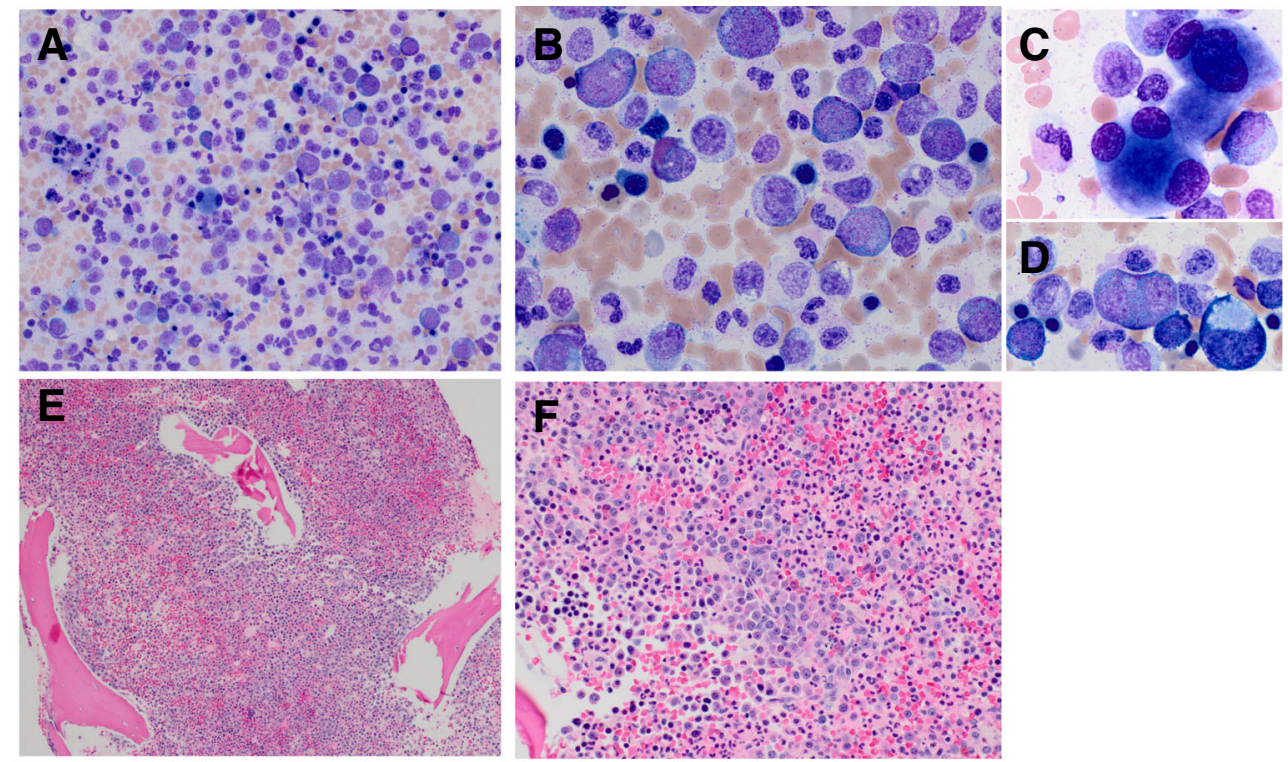
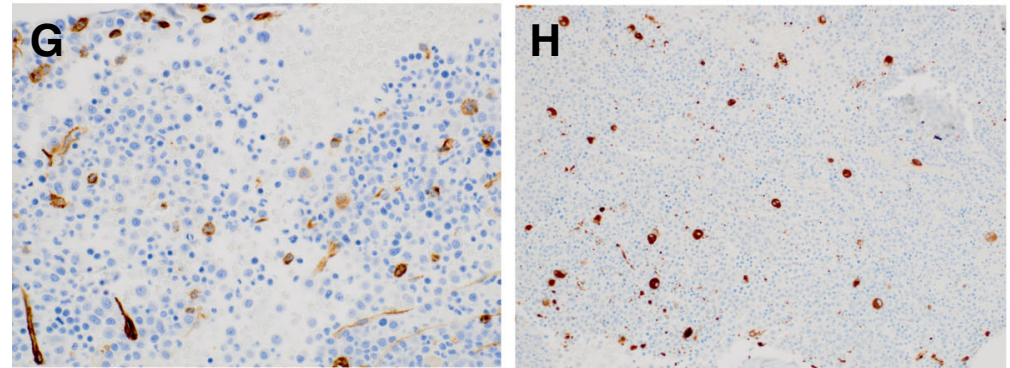

Fig. 3 Monosomy 7 syndrome due to GATA2 mutation. Representative bone marrow aspirate and biopsy images of the marrow from a 19-yearold male with "monosomy 7 syndrome." The patient presented with easy bruising and a leukocytosis of $39.0 \times 10^{3}$ cells/uL with $2 \%$ circulating blasts and the presence of metamyelocytoes and myelocytes on the peripheral blood smear. The absolute monocyte count was $2.15 \times 10^{3}$ cells/ $\mathrm{uL}$. The Hgb was $10.0 \mathrm{~g} / \mathrm{dL}$, and the platelet count was $76 \times 10^{3}$ cells $/ \mathrm{uL}$. Cytogenetic studies showed monosomy 7 in 20 out of 20 metaphases. Molecular analysis confirmed a pathogenic GATA2 mutation in the critical zinc-finger region. a, b Bone marrow aspirate $(\times 200$ and $\times 400)$ showed a hypercellular myeloid predominant marrow. The myeloid elements were left shifted and dysplastic with hypolobated forms. The

While the use of hypomethylating agents has been shown to improve overall survival (OS) in high-risk adult MDS patients [18], these agents have some limitations since the response can take several months [68] and are associated with a risk of febrile neutropenia $[18,49,71]$. While isolated cases, particularly in the palliative care setting, have shown a possible response, their use has not been systematically evaluated in children and should be limited to clinical trials and compassionate use.

\section{Prognosis}

Some patients with low-grade pediatric MDS, in particular $\mathrm{RCC}$ without high-risk cytogenetic abnormalities, need for transfusions or risk of neutropenia have relatively stable erythroid series showed megaloblastoid maturation. Megakaryocytes showed frequent dysplastic forms. c High-power view $(\times 1000)$ of two dysplastic megakaryocytes with separated nuclear lobes. d Illustration of dysplastic early promonocyte to monocyte with two nuclei and nuclear satellite. e Bone marrow biopsy $(\times 100)$ showed a hypercellular marrow with $\mathbf{f}$ myeloid predominance and clusters of early myeloid forms $(\times 200)$. g Immunohistochemistry (IHC) for CD34 showed scattered blasts comprising less than $5 \%$ of the overall cellularity (200x). h ICH for CD61 highlighted increased often smaller sized megakaryocytes, including micromegakaryocytes, small hypolobated forms, and dysplastic forms with separated nuclear lobes $(\times 100)$

disease for weeks to years. In this setting, a "watch and wait" strategy may be indicated. Nevertheless, pediatric MDS patients remain at risk for clonal transformation and progression to leukemia that is estimated at about $30 \%$ for patients with RCC over 5 years. While monosomy 7 and complex karyotype ( $\geq 3$ abnormalities) are known to be associated with increased risk for disease progression to leukemia, it is difficult to predict when this will occur $[26,33,45]$. Given the clinical heterogeneity and lack of precise prognostic factors, guidelines on the optimal timing for HSCT and the need for upfront chemotherapy in advanced MDS do not currently exist.

Reported outcomes of pediatric MDS after HSCT vary. Earlier studies showed a 3-year OS between 18-74 \% depending on stage, with RAEB-T having the worst outcomes [93]. A recent large study from the Center of International Blood and 


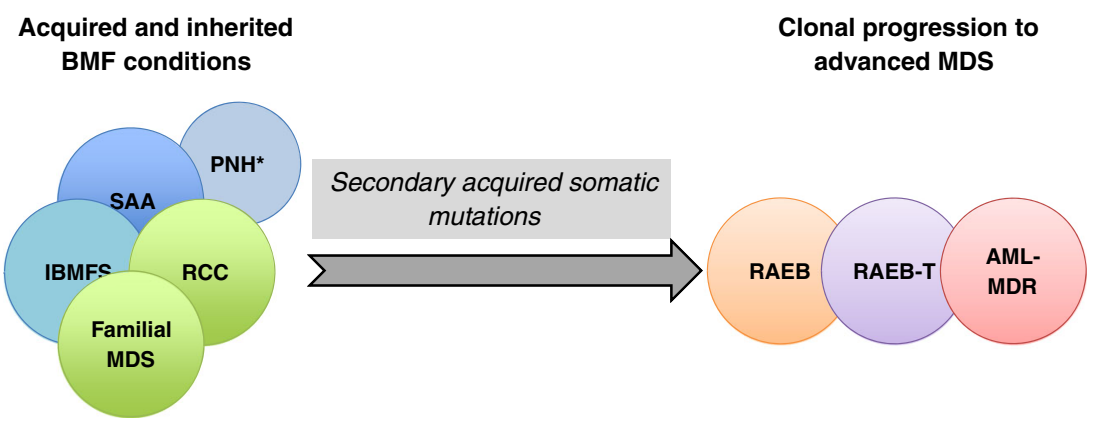

Fig. 4 Relationship between marrow failure conditions and myelodysplastic syndromes (MDS) and disease progression to myeloid leukemia. This diagram illustrates the clinical and possible genetic overlaps and relationships between bone marrow failure $(B M F)$ conditions, low-grade MDS, and high-grade MDS with progression to acute myeloid leukemia $(A M L)$. The left panel shows the overlap between acquired BMF conditions such as severe aplastic anemia ( $S A A)$, IBMFS, refractory cytopenia of childhood $(R C C)$, and familial MDS such as patients with GATA2 haploinsufficiency. These conditions present with cytopenias and a hypocellular marrow in most cases and share significant clinical and histopathologic overlap suggesting a possible underlying inherited genetic defect in patients with pediatric MDS. Most SAA is thought to be an immunologic process. Immune dysregulation may even play a role in RCC, since some of these patients respond to

Marrow Transplant Research showed [89] an 8-year disease free survival of $40-65 \%$ for RCC and $28-48 \%$ for RAEB/ RAEB-T and a 1-year transplant-related mortality of 13-42\%. The European Working Group of Myelodysplastic Syndromes in Childhood reported more favorable outcomes for children with advanced MDS with a 5-year OS of $63 \%$ with a TRM and RI of $21 \%$, each [77].

Recent evidence supports the hypothesis that somatic clonal evolution in the context of an underlying inherited predisposition to MDS and BMF may indicate clinical disease progression (Fig. 4). For example, acquired somatic $A S X L 1 \mathrm{mu}-$ tations have been identified in patients with GATA2 haploinsufficiency and were associated with progression from MDS to leukemia [86]. With the rapid progression of NGS technologies, we may be equipped to identify more patients at risk for leukemic transformation prior to overt clinical leukemia.

\section{Conclusions}

Pediatric MDS is a rare and heterogeneous group of clonal hematopoietic stem cell disorders that remain difficult to diagnosis. While emerging evidence suggests that an underlying genetic predisposition might be the cause for pediatric MDS, the molecular underpinnings remain unclear. Pediatric MDS is diagnosed using the 2008 WHO classification system. Within this classification scheme, RCC remains a provisional entity and its clinical implications are immunosuppressive therapy; a significant subset of patients with SAA and RCC do not respond to IST suggesting an underlying stem cell defect or exhaustion possible due to an inherited genetic defect in some of those patients. *PHN clones can develop secondary to SAA but are also seen in $\mathrm{RCC}$. The right panel shows the other end of the disease spectrum with high-grade pediatric MDS such as a RAEB and RAEB-T with progression to AML. It has been hypothesized that an underlying genetic defect on a germline level is the underlying basis of many cases of pediatric MDS, which predisposes them to marrow failure, dysplastic hematopoiesis, and risk for clonal evolution. Secondary-acquired mutations are likely involved in clonal evolution and disease progression to advanced MDS and AML. Identifying such somatic clonal markers might help predict which patients are at high risk for rapid disease progression and inform therapeutic interventions and timing to transplant

uncertain. Diagnosis of pediatric MDS often requires analysis by a team of experienced pediatric hematologists and hematopathologists, in conjunction with multiple molecular studies. With the rapid advancement of NGS technologies, we hope to diagnose and characterize these disorders more effectively in the future. Comprehensive multidisciplinary analysis of these rare patients in large collaborative studies will be valuable for improving in our understanding of these disorders.

Conflict of interest The author declares that she has no competing interests.

Funding This study was funded by the National Institutes of Health career development award from the National Cancer Institute (1K08CA140723).

Ethical approval This article does not contain any studies with human participants or animals performed by any of the authors.

\section{References}

1. (1997) Forty-four cases of childhood myelodysplasia with cytogenetics, documented by the Groupe Francais de Cytogenetique Hematologique. Leukemia 11: 1478-1485

2. Aalbers AM, van der Velden VH, Yoshimi A, Fischer A, Noellke P, Zwaan CM, Baumann I, Beverloo HB, Dworzak M, Hasle H et al (2014) The clinical relevance of minor paroxysmal nocturnal hemoglobinuria clones in refractory cytopenia of childhood: a prospective study by EWOG-MDS. Leukemia 28:189-192. doi:10. 1038/leu.2013.195 
3. Alter BP (2003) Cancer in Fanconi anemia, 1927-2001. Cancer 97: 425-440. doi:10.1002/cncr.11046

4. Alter BP, Scalise A, McCombs J, Najfeld V (1993) Clonal chromosomal abnormalities in Fanconi's anaemia: what do they really mean? Br J Haematol 85:627-630

5. Antillon F, Raimondi SC, Fairman J, Liang H, Nagarajan L, Head D, Ribeiro RC (1998) 5q- in a child with refractory anemia with excess blasts: similarities to $5 \mathrm{q}$ - syndrome in adults. Cancer Genet Cytogenet 105:119-122

6. Bain BJ (2003) Di Guglielmo and his syndromes. Br J Haematol 120:939-943

7. Baumann I, Fuhrer M, Behrendt S, Campr V, Csomor J, Furlan I, de Haas V, Kerndrup G, Leguit RJ, De Paepe P et al (2012) Morphological differentiation of severe aplastic anaemia from hypocellular refractory cytopenia of childhood: reproducibility of histopathological diagnostic criteria. Histopathology 61:10-17. doi: 10.1111/j.1365-2559.2011.04156.x

8. Bigley V, Collin M (2011) Dendritic cell, monocyte, B and NK lymphoid deficiency defines the lost lineages of a new GATA-2 dependent myelodysplastic syndrome. Haematologica 96:10811083. doi:10.3324/haematol.2011.048355

9. Bigley V, Haniffa M, Doulatov S, Wang XN, Dickinson R, McGovern N, Jardine L, Pagan S, Dimmick I, Chua I et al (2011) The human syndrome of dendritic cell, monocyte, B and NK lymphoid deficiency. J Exp Med 208:227-234. doi:10.1084/jem. 20101459

10. Bowen DT (2013) Occupational and environmental etiology of MDS. Best Pract Res Clin Haematol 26:319-326. doi:10.1016/j. beha.2013.09.002

11. Calvo KR, Vinh DC, Maric I, Wang W, Noel P, Stetler-Stevenson M, Arthur DC, Raffeld M, Dutra A, Pak Eet al Myelodysplasia in autosomal dominant and sporadic monocytopenia immunodeficiency syndrome: diagnostic features and clinical implications. Haematologica 96: 1221-1225 Doi: 10.3324/haematol.2011. 041152

12. Calvo KR, Vinh DC, Maric I, Wang W, Noel P, Stetler-Stevenson M, Arthur DC, Raffeld M, Dutra A, Pak E et al (2011) Myelodysplasia in autosomal dominant and sporadic monocytopenia immunodeficiency syndrome: diagnostic features and clinical implications. Haematologica 96:1221-1225. doi:10. 3324/haematol.2011.041152

13. Cancer TIAR (2008) Childhood myelodysplastic syndrome. In: Swerdlow SH CE, Harris NL, Jaffe ES, Pileri SA, Stein H, Thiele J, Vardimaan JW (eds) WHO classification of tumours of haematopoietic and lymphoid tissues, 4th edn. IARC, City, pp 104-107

14. Cantu Rajnoldi A, Fenu S, Kerndrup G, van Wering ER, Niemeyer CM, Baumann I, European Working Group on Myelodysplastic Syndromes in C (2005) Evaluation of dysplastic features in myelodysplastic syndromes: experience from the morphology group of the European Working Group of MDS in Childhood (EWOG-MDS). Ann Hematol 84:429-433. doi:10.1007/s00277005-1034-4

15. Della Porta MG, Picone C, Pascutto C, Malcovati L, Tamura H, Handa H, Czader M, Freeman S, Vyas P, Porwit A et al (2012) Multicenter validation of a reproducible flow cytometric score for the diagnosis of low-grade myelodysplastic syndromes: results of a European LeukemiaNET study. Haematologica 97:1209-1217. doi: 10.3324/haematol.2011.048421

16. Dickinson RE, Griffin H, Bigley V, Reynard LN, Hussain R, Haniffa M, Lakey JH, Rahman T, Wang XN, McGovern N et al (2011) Exome sequencing identifies GATA-2 mutation as the cause of dendritic cell, monocyte, B and NK lymphoid deficiency. Blood 118:2656-2658. doi:10.1182/blood-2011-06-360313

17. Elghetany MT (2007) Myelodysplastic syndromes in children: a critical review of issues in the diagnosis and classification of 887 cases from 13 published series. Arch Pathol Lab Med 131:1110 1116. doi:10.1043/1543-2165(2007)131[1110:MSICAC]2.0.CO;2

18. Fenaux P, Mufti GJ, Hellstrom-Lindberg E, Santini V, Finelli C, Giagounidis A, Schoch R, Gattermann N, Sanz G, List A et al (2009) Efficacy of azacitidine compared with that of conventional care regimens in the treatment of higher-risk myelodysplastic syndromes: a randomised, open-label, phase III study. Lancet Oncol 10:223-232. doi:10.1016/S1470-2045(09)70003-8

19. Fleming MD (2011) Congenital sideroblastic anemias: iron and heme lost in mitochondrial translation. Hematology / the Education Program of the American Society of Hematology American Society of Hematology Education Program 2011:525531. doi:10.1182/asheducation-2011.1.525

20. Font P, Subira D (2008) Expression of CD7 in myelodysplastic syndromes (MDS): is this a truly prognostic factor? Leuk Res 32: 185-186. doi:10.1016/j.leukres.2007.01.016

21. Font P, Subira D, Mtnez-Chamorro C, Castanon S, Arranz E, Ramiro S, Gil-Fernandez JJ, Lopez-Pascual J, Alonso A, PerezSaenz MA et al (2006) Evaluation of CD7 and terminal deoxynucleotidyl transferase (TdT) expression in CD34+ myeloblasts from patients with myelodysplastic syndrome. Leuk Res 30: 957-963. doi:10.1016/j.leukres.2005.11.026

22. Forester CM, Sartain SE, Guo D, Harris MH, Weinberg OK, Fleming MD, London WB, Williams DA, Hofmann I (2015) Pediatric aplastic anemia and refractory cytopenia: a retrospective analysis assessing outcomes and histomorphologic predictors. Am J Hematol: Doi 10.1002/ajh.23937

23. Gabreyes AA, Abbasi HN, Forbes KP, McQuaker G, Duncan A, Morrison I (2013) Hypocupremia associated cytopenia and myelopathy: a national retrospective review. Eur J Haematol 90:1-9. doi:10.1111/ejh.12020

24. Ganapathi KA, Townsley DM, Hsu AP, Arthur DC, Zerbe CS, Cuellar-Rodriguez J, Hickstein DD, Rosenzweig SD, Braylan RC, Young NS et al (2015) GATA2 deficiency-associated bone marrow disorder differs from idiopathic aplastic anemia. Blood 125:56-70. doi:10.1182/blood-2014-06-580340

25. Germing U, Strupp C, Kuendgen A, Isa S, Knipp S, Hildebrandt B, Giagounidis A, Aul C, Gattermann N, Haas R (2006) Prospective validation of the WHO proposals for the classification of myelodysplastic syndromes. Haematologica 91:1596-1604

26. Gohring G, Michalova K, Beverloo HB, Betts D, Harbott J, Haas OA, Kerndrup G, Sainati L, Bergstraesser E, Hasle H et al (2010) Complex karyotype newly defined: the strongest prognostic factor in advanced childhood myelodysplastic syndrome. Blood 116: 3766-3769. doi:10.1182/blood-2010-04-280313

27. Hahn CN, Chong CE, Carmichael CL, Wilkins EJ, Brautigan PJ, Li XC, Babic M, Lin M, Carmagnac A, Lee YK et al (2011) Heritable GATA2 mutations associated with familial myelodysplastic syndrome and acute myeloid leukemia. Nat Genet 43:1012-1017. doi:10.1038/ng.913

28. Hahn CN, Chong CE, Carmichael CL, Wilkins EJ, Brautigan PJ, Li XC, Babic M, Lin M, Carmagnac A, Lee YKet al Heritable GATA2 mutations associated with familial myelodysplastic syndrome and acute myeloid leukemia. Nat Genet 43: 1012-1017 Doi: 10.1038/ ng.913

29. Hasegawa D, Chen X, Hirabayashi S, Ishida $Y$, Watanabe S, Zaike Y, Tsuchida M, Masunaga A, Yoshimi A, Hama A et al (2014) Clinical characteristics and treatment outcome in 65 cases with refractory cytopenia of childhood defined according to the WHO 2008 classification. Br J Haematol 166:758-766. doi:10.1111/bjh. 12955

30. Hasle H (2007) Myelodysplastic and myeloproliferative disorders in children. Curr Opin Pediatr 19:1-8. doi:10.1097/MOP. 0b013e3280128ce8

31. Hasle H, Arico M, Basso G, Biondi A, Cantu Rajnoldi A, Creutzig U, Fenu S, Fonatsch C, Haas OA, Harbott J et al (1999) 
Myelodysplastic syndrome, juvenile myelomonocytic leukemia, and acute myeloid leukemia associated with complete or partial monosomy 7. European Working Group on MDS in Childhood (EWOG-MDS). Leukemia 13:376-385

32. Hasle H, Kerndrup G, Jacobsen BB (1995) Childhood myelodysplastic syndrome in Denmark: incidence and predisposing conditions. Leukemia 9:1569-1572

33. Hasle H, Niemeyer CM, Chessells JM, Baumann I, Bennett JM, Kerndrup G, Head DR (2003) A pediatric approach to the WHO classification of myelodysplastic and myeloproliferative diseases. Leukemia 17:277-282. doi:10.1038/sj.leu.2402765

34. Hasle H, Wadsworth LD, Massing BG, McBride M, Schultz KR (1999) A population-based study of childhood myelodysplastic syndrome in British Columbia, Canada. Br J Haematol 106:10271032

35. Hirabayashi S, Flotho C, Moetter J, Heuser M, Hasle H, Gruhn B, Klingebiel T, Thol F, Schlegelberger B, Baumann Iet al Spliceosomal gene aberrations are rare, coexist with oncogenic mutations, and are unlikely to exert a driver effect in childhood MDS and JMML. Blood 119: e96-e99 Doi: 10.1182/blood-2011-12395087

36. Hofmann I, Krasker J, Campagna D, Kierstead D, Schmitz-Abe K, Markianos K, Lee M, Sieff C, Williams DA, Fleming MD (2013) GATA2 mutations in pediatric myelodysplastic syndrome and bone marrow failure disorders. Pediatr Blood Cancer 60:S2

37. Hofmann I, Krasker J, Campagna D, Kierstead D, Schmitz-Abe K, Markianos K, Lee M, Sieff C, Williams DA, Fleming MD (2013) GATA2 mutations in pediatric myelodysplastic syndrome and bone marrow failure disorders. Leuk Res 37:S20

38. Hsu AP, Johnson KD, Falcone EL, Sanalkumar R, Sanchez L, Hickstein DD, Cuellar-Rodriguez J, Lemieux JE, Zerbe CS, Bresnick EH et al (2013) GATA2 haploinsufficiency caused by mutations in a conserved intronic element leads to MonoMAC syndrome. Blood 121(3830-3837):S3831-S3837. doi:10.1182/ blood-2012-08-452763

39. Hsu AP, Johnson KD, Falcone EL, Sanalkumar R, Sanchez L, Hickstein DD, Cuellar-Rodriguez J, Lemieux JE, Zerbe CS, Bresnick EHet al GATA2 haploinsufficiency caused by mutations in a conserved intronic element leads to MonoMAC syndrome. Blood 121: 3830-3837, S3831-3837 Doi: 10.1182/blood-2012$08-452763$

40. Hsu AP, Sampaio EP, Khan J, Calvo KR, Lemieux JE, Patel SY, Frucht DM, Vinh DC, Auth RD, Freeman AF et al Mutations in GATA2 are associated with the autosomal dominant and sporadic monocytopenia and mycobacterial infection (MonoMAC) syndrome. Blood 118: 2653-2655 Doi: 10.1182/blood-2011-05356352

41. Hsu AP, Sampaio EP, Khan J, Calvo KR, Lemieux JE, Patel SY, Frucht DM, Vinh DC, Auth RD, Freeman AF et al (2011) Mutations in GATA2 are associated with the autosomal dominant and sporadic monocytopenia and mycobacterial infection (MonoMAC) syndrome. Blood 118:2653-2655. doi:10.1182/ blood-2011-05-356352

42. Jaiswal S, Fontanillas P, Flannick J, Manning A, Grauman PV, Mar BG, Lindsley RC, Mermel CH, Burtt N, Chavez A et al (2014) Age-related clonal hematopoiesis associated with adverse outcomes. N Eng1 J Med 371:2488-2498. doi:10.1056/ NEJMoa1408617

43. Johnson KD, Hsu AP, Ryu MJ, Wang J, Gao X, Boyer ME, Liu Y, Lee Y, Calvo KR, Keles S et al (2012) Cis-element mutated in GATA2-dependent immunodeficiency governs hematopoiesis and vascular integrity. J Clin Invest 122:3692-3704. doi:10.1172/ JCI61623

44. Kaneko H, Misawa S, Horiike S, Nakai H, Kashima K (1995) TP53 mutations emerge at early phase of myelodysplastic syndrome and are associated with complex chromosomal abnormalities. Blood 85: 2189-2193

45. Kardos G, Baumann I, Passmore SJ, Locatelli F, Hasle H, Schultz KR, Stary J, Schmitt-Graeff A, Fischer A, Harbott J et al (2003) Refractory anemia in childhood: a retrospective analysis of 67 patients with particular reference to monosomy 7. Blood 102:19972003. doi:10.1182/blood-2002-11-3444

46. Kazenwadel J, Secker GA, Liu YJ, Rosenfeld JA, Wildin RS, Cuellar-Rodriguez J, Hsu AP, Dyack S, Fernandez CV, Chong CEet al Loss-of-function germline GATA2 mutations in patients with MDS/AML or MonoMAC syndrome and primary lymphedema reveal a key role for GATA2 in the lymphatic vasculature. Blood 119: 1283-1291 Doi: 10.1182/blood-2011-08-374363

47. Kazenwadel J, Secker GA, Liu YJ, Rosenfeld JA, Wildin RS, Cuellar-Rodriguez J, Hsu AP, Dyack S, Fernandez CV, Chong CE et al (2012) Loss-of-function germline GATA2 mutations in patients with MDS/AML or MonoMAC syndrome and primary lymphedema reveal a key role for GATA2 in the lymphatic vasculature. Blood 119:1283-1291. doi:10.1182/blood-2011-08-374363

48. Knerr I, Metzler M, Niemeyer CM, Holter W, Gerecke A, Baumann I, Trollmann R, Repp R (2003) Hematologic features and clinical course of an infant with Pearson syndrome caused by a novel deletion of mitochondrial DNA. J Pediatr Hematol Oncol 25:948-951

49. Lubbert M, Suciu S, Baila L, Ruter BH, Platzbecker U, Giagounidis A, Selleslag D, Labar B, Germing U, Salih HR et al Low-dose decitabine versus best supportive care in elderly patients with intermediate- or high-risk myelodysplastic syndrome (MDS) ineligible for intensive chemotherapy: final results of the randomized phase III study of the European Organisation for Research and Treatment of Cancer Leukemia Group and the German MDS Study Group. J Clin Oncol 29: 1987-1996 Doi: 10.1200/JCO. 2010.30.9245

50. Luna-Fineman S, Shannon KM, Atwater SK, Davis J, Masterson M, Ortega J, Sanders J, Steinherz P, Weinberg V, Lange BJ (1999) Myelodysplastic and myeloproliferative disorders of childhood: a study of 167 patients. Blood 93:459-466

51. Maarek O, Jonveaux P, Le Coniat M, Derre J, Berger R (1996) Faconi anemia and bone marrow clonal chromosome abnormalities. Leukemia 10:1700-1704

52. Matsuda A, Germing U, Jinnai I, Iwanaga M, Misumi M, Kuendgen A, Strupp C, Miyazaki Y, Tsushima H, Sakai M et al (2007) Improvement of criteria for refractory cytopenia with multilineage dysplasia according to the WHO classification based on prognostic significance of morphological features in patients with refractory anemia according to the FAB classification. Leukemia 21:678-686. doi:10.1038/sj.leu.2404571

53. Niemeyer CM, Baumann I (2011) Classification of childhood aplastic anemia and myelodysplastic syndrome. Hematology / the Education Program of the American Society of Hematology American Society of Hematology Education Program 2011:84 89. doi:10.1182/asheducation-2011.1.84

54. Niemeyer CM, Baumann I (2008) Myelodysplastic syndrome in children and adolescents. Semin Hematol 45:60-70. doi:10.1053/ j.seminhematol.2007.10.006

55. Niemeyer CM, Kratz CP, Hasle H (2005) Pediatric myelodysplastic syndromes. Curr Treat Options Oncol 6:209-214

56. Ogata K, Della Porta MG, Malcovati L, Picone C, Yokose N, Matsuda A, Yamashita T, Tamura H, Tsukada J, Dan K (2009) Diagnostic utility of flow cytometry in low-grade myelodysplastic syndromes: a prospective validation study. Haematologica 94: 1066-1074. doi:10.3324/haematol.2009.008532

57. Ogata K, Nakamura K, Yokose N, Tamura H, Tachibana M, Taniguchi O, Iwakiri R, Hayashi T, Sakamaki H, Murai Y et al (2002) Clinical significance of phenotypic features of blasts in patients with myelodysplastic syndrome. Blood 100:3887-3896. doi: 10.1182/blood-2002-01-0222 
58. Ogata K, Yoshida Y (2005) Clinical implications of blast immunophenotypes in myelodysplastic syndromes. Leuk Lymphoma 46:1269-1274. doi:10.1080/10428190500142155

59. Ostergaard P, Simpson MA, Connell FC, Steward CG, Brice G, Woollard WJ, Dafou D, Kilo T, Smithson S, Lunt P et al (2011) Mutations in GATA2 cause primary lymphedema associated with a predisposition to acute myeloid leukemia (Emberger syndrome). Nat Genet 43:929-931. doi:10.1038/ng.923

60. Ostergaard P, Simpson MA, Connell FC, Steward CG, Brice G, Woollard WJ, Dafou D, Kilo T, Smithson S, Lunt P et al Mutations in GATA2 cause primary lymphedema associated with a predisposition to acute myeloid leukemia (Emberger syndrome). Nat Genet 43: 929-931 Doi: 10.1038/ng.923

61. Papaemmanuil E, Cazzola M, Boultwood J, Malcovati L, Vyas P, Bowen D, Pellagatti A, Wainscoat JS, Hellstrom-Lindberg E, Gambacorti-Passerini C et al Somatic SF3B1 mutation in myelodysplasia with ring sideroblasts. N Engl J Med 365: 1384 1395 Doi 10.1056/NEJMoa1103283

62. Pasquet M, Bellanne-Chantelot C, Tavitian S, Prade N, Beaupain B, Larochelle O, Petit A, Rohrlich P, Ferrand C, Van Den Neste E et al (2013) High frequency of GATA2 mutations in patients with mild chronic neutropenia evolving to MonoMac syndrome, myelodysplasia, and acute myeloid leukemia. Blood 121:822829. doi:10.1182/blood-2012-08-447367

63. Passmore SJ, Chessells JM, Kempski H, Hann IM, Brownbill PA, Stiller CA (2003) Paediatric myelodysplastic syndromes and juvenile myelomonocytic leukaemia in the UK: a population-based study of incidence and survival. Br J Haematol 121:758-767

64. Passmore SJ, Hann IM, Stiller CA, Ramani P, Swansbury GJ, Gibbons B, Reeves BR, Chessells JM (1995) Pediatric myelodysplasia: a study of 68 children and a new prognostic scoring system. Blood 85:1742-1750

65. Pedersen-Bjergaard J, Andersen MK, Christiansen DH, Nerlov C (2002) Genetic pathways in therapy-related myelodysplasia and acute myeloid leukemia. Blood 99:1909-1912

66. Pedersen-Bjergaard J, Christiansen DH, Andersen MK, Skovby F (2002) Causality of myelodysplasia and acute myeloid leukemia and their genetic abnormalities. Leukemia 16:2177-2184. doi:10. 1038/sj.leu.2402764

67. Sasaki H, Manabe A, Kojima S, Tsuchida M, Hayashi Y, Ikuta K, Okamura I, Koike K, Ohara A, Ishii E et al (2001) Myelodysplastic syndrome in childhood: a retrospective study of 189 patients in Japan. Leukemia 15:1713-1720

68. Sekeres MA, Cutler C How we treat higher-risk myelodysplastic syndromes. Blood 123: 829-836 Doi: 10.1182/blood-2013-08496935

69. Shikano T, Ishikawa Y, Anakura M (1992) Myelodysplastic syndrome with partial deletion of the long arm of chromosome 5: first report of a case in a child. Acta Paediatr Jpn 34:539-542

70. Sieff CA, Chessells JM, Harvey BA, Pickthall VJ, Lawler SD (1981) Monosomy 7 in childhood: a myeloproliferative disorder. Br J Haematol 49:235-249

71. Silverman LR, McKenzie DR, Peterson BL, Holland JF, Backstrom JT, Beach CL, Larson RA (2006) Further analysis of trials with azacitidine in patients with myelodysplastic syndrome: studies 8421, 8921, and 9221 by the Cancer and Leukemia Group B. J Clin Oncol 24:3895-3903. doi:10.1200/JCO.2005.05.4346

72. Smith AR, Christiansen EC, Wagner JE, Cao Q, MacMillan ML, Stefanski HE, Trotz BA, Burke MJ, Verneris MR (2013) Early hematopoietic stem cell transplant is associated with favorable outcomes in children with MDS. Pediatr Blood Cancer 60:705-710. doi: $10.1002 /$ pbc. 24390

73. Smith AR, Christiansen EC, Wagner JE, Cao Q, MacMillan ML, Stefanski HE, Trotz BA, Burke MJ, Verneris MR Early hematopoietic stem cell transplant is associated with favorable outcomes in children with MDS. Pediatr Blood Cancer 60: 705-710 Doi 10. $1002 / p b c .24390$

74. Spinner MA, Sanchez LA, Hsu AP, Shaw PA, Zerbe CS, Calvo KR, Arthur DC, Gu W, Gould CM, Brewer CC et al (2014) GATA2 deficiency: a protean disorder of hematopoiesis, lymphatics, and immunity. Blood 123:809-821. doi:10.1182/blood-2013-07515528

75. Spinner MA, Sanchez LA, Hsu AP, Shaw PA, Zerbe CS, Calvo KR, Arthur DC, Gu W, Gould CM, Brewer CCet al GATA2 deficiency: a protean disorder of hematopoiesis, lymphatics, and immunity. Blood 123: 809-821 Doi: 10.1182/blood-2013-07-515528

76. Strahm B, Locatelli F, Bader P, Ehlert K, Kremens B, Zintl F, Fuhrer M, Stachel D, Sykora KW, Sedlacek P et al (2007) Reduced intensity conditioning in unrelated donor transplantation for refractory cytopenia in childhood. Bone Marrow Transplant 40:329-333. doi: 10.1038/sj.bmt. 1705730

77. Strahm B, Nollke P, Zecca M, Korthof ET, Bierings M, Furlan I, Sedlacek P, Chybicka A, Schmugge M, Bordon V et al (2011) Hematopoietic stem cell transplantation for advanced myelodysplastic syndrome in children: results of the EWOGMDS 98 study. Leukemia 25:455-462. doi:10.1038/leu.2010.297

78. Tsurusawa M, Manabe A, Hayashi Y, Akiyama Y, Kigasawa H, Inada H, Noguchi Y, Sawai N, Kobayashi R, Nagatoshi Y et al (2005) Therapy-related myelodysplastic syndrome in childhood: a retrospective study of 36 patients in Japan. Leuk Res 29:625-632. doi:10.1016/j.leukres.2004.11.018

79. Uyttebroeck A, Brock P, De Groote B, Renard M, Dal Cin P, Van den Berghe H, Casteels-Van Daele M (1995) 5q- syndrome in a child. Cancer Genet Cytogenet 80:121-123

80. van de Loosdrecht AA, Westers TM, Westra AH, Drager AM, van der Velden VH, Ossenkoppele GJ (2008) Identification of distinct prognostic subgroups in low- and intermediate-1-risk myelodysplastic syndromes by flow cytometry. Blood 111:10671077. doi:10.1182/blood-2007-07-098764

81. van den Heuvel-Eibrink MM (2007) Paroxysmal nocturnal hemoglobinuria in children. Paediatr Drugs 9:11-16

82. Veltroni M, Sainati L, Zecca M, Fenu S, Tridello G, Testi AM, Merlone AD, Buldini B, Leszl A, Lo Nigro L et al (2009) Advanced pediatric myelodysplastic syndromes: can immunophenotypic characterization of blast cells be a diagnostic and prognostic tool? Pediatr Blood Cancer 52:357-363. doi:10. $1002 / p b c .21874$

83. Verburgh E, Achten R, Louw VJ, Brusselmans C, Delforge M, Boogaerts M, Hagemeijer A, Vandenberghe P, Verhoef G (2007) A new disease categorization of low-grade myelodysplastic syndromes based on the expression of cytopenia and dysplasia in one versus more than one lineage improves on the WHO classification. Leukemia 21:668-677. doi:10.1038/sj.leu.2404564

84. Vinh DC, Patel SY, Uzel G, Anderson VL, Freeman AF, Olivier KN, Spalding C, Hughes S, Pittaluga S, Raffeld M et al (2010) Autosomal dominant and sporadic monocytopenia with susceptibility to mycobacteria, fungi, papillomaviruses, and myelodysplasia. Blood 115:1519-1529. doi:10.1182/blood-2009-03-208629

85. Visconte V, Makishima H, Jankowska A, Szpurka H, Traina F, Jerez A, O'Keefe C, Rogers HJ, Sekeres MA, Maciejewski JPet al SF3B1, a splicing factor is frequently mutated in refractory anemia with ring sideroblasts. Leukemia 26: 542-545 Doi: 10.1038/leu. 2011.232

86. West RR, Hsu AP, Holland SM, Cuellar-Rodriguez J, Hickstein DD (2014) Acquired ASXL1 mutations are common in patients with inherited GATA2 mutations and correlate with myeloid transformation. Haematologica 99:276-281. doi:10.3324/haematol.2013. 090217

87. Westers TM, Ireland R, Kern W, Alhan C, Balleisen JS, Bettelheim P, Burbury K, Cullen M, Cutler JA, Della Porta MG et al (2012) Standardization of flow cytometry in myelodysplastic syndromes: a 
report from an international consortium and the European LeukemiaNet Working Group. Leukemia 26:1730-1741. doi:10. 1038/leu.2012.30

88. Wong TE, Calicchio ML, Fleming MD, Shimamura A, Harris MH (2010) SBDS protein expression patterns in the bone marrow. Pediatr Blood Cancer 55:546-549. doi:10.1002/pbc.22573

89. Woodard P, Carpenter PA, Davies SM, Gross TG, He W, Zhang MJ, Horn BN, Margolis DA, Perentesis JP, Sanders JEet al Unrelated donor bone marrow transplantation for myelodysplastic syndrome in children. Biol Blood Marrow Transplant 17: 723-728 Doi: 10. 1016/j.bbmt.2010.08.016

90. Yang W, Zhang P, Hama A, Ito M, Kojima S, Zhu X (2012) Diagnosis of acquired bone marrow failure syndrome during childhood using the 2008 World Health Organization classification system. Int J Hematol 96:34-38. doi:10.1007/s12185012-1092-z

91. Yoshida K, Sanada M, Shiraishi Y, Nowak D, Nagata Y, Yamamoto R, Sato Y, Sato-Otsubo A, Kon A, Nagasaki Met al Frequent pathway mutations of splicing machinery in myelodysplasia. Nature 478: 64-69 Doi: 10.1038/nature10496

92. Yoshimi A, Niemeyer C, Baumann I, Schwarz-Furlan S, Schindler D, Ebell W, Strahm B (2013) High incidence of Fanconi anaemia in patients with a morphological picture consistent with refractory cytopenia of childhood. Br J Haematol 160:109-111. doi:10.1111/ bjh. 12083

93. Yusuf U, Frangoul HA, Gooley TA, Woolfrey AE, Carpenter PA, Andrews RG, Deeg HJ, Appelbaum FR, Anasetti C, Storb R et al (2004) Allogeneic bone marrow transplantation in children with myelodysplastic syndrome or juvenile myelomonocytic leukemia: the Seattle experience. Bone Marrow Transplant 33:805-814. doi: 10.1038/sj.bmt. 1704438

94. Zhang MY, Churpek JE, Keel SB, Walsh T, Lee MK, Loeb KR, Gulsuner S, Pritchard CC, Sanchez-Bonilla M, Delrow JJ et al (2015) Germline ETV6 mutations in familial thrombocytopenia and hematologic malignancy. Nat Genet 47:180-185. doi:10. 1038/ng.3177 